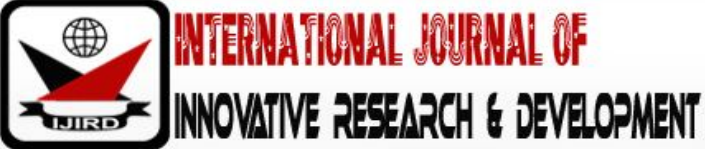

ISSN 2278 - 0211 (Online)

\section{Supervision in Nursing Practice: The Pathway to Career Adaptability}

Ebtesam Saeed Ahmed Abd-Elrhaman

Lecturer, Department of Nursing Administration, Benha University, Egypt

Aya Ghoneimy Hasanin Ghoneimy

Lecturer, Department of Nursing Administration, Benha University, Egypt

\begin{abstract}
:
Background: Supervision is one of the techniques used to improve nurses' competencies as; it provides essential support for nurses progressing into advanced practice to foster professional development, and career adaptability. Aim: The present study aimed to evaluate the effect of educational program about clinical supervision for first line managers on staff nurses' career adaptability. Research Design: Quasi experimental design was utilized. Study Setting: the study was conducted in all units at Benha University Hospital, the total number of the studied units were (57) units. The study sample was: All the available head nurses and their assistants (88), and convenient sample of staff nurses (176) who are working in the abovementioned study setting. Tools of data collection: Three tools were used: (1) Clinical Supervision Knowledge Questionnaire, (2) Observational checklist of first line managers' performance, and (3) Career Adapt-Abilities Scale (CAAS). Results: The findings of this study showed that there was a highly statistical significant improvement in first line managers' knowledge and performance regarding clinical supervision thorough program. Moreover, there was a highly statistical significant improvement in staff nurses' level of career adaptability. Conclusion: The study concluded that there was a highly statistical positive correlation between first line managers' clinical supervision performance and staff nurses' career adaptability. Recommendations: Setting clear responsibilities for both nursing supervisor and supervisee through a constructive clinical supervision policies and procedures, providing supportive healthy work environment that help nurses to reflect on their personal and professional work-related issues with their clinical supervisors that help in enhancing their career adaptability, and integrating career adaptability in nursing education.
\end{abstract}

Keywords: Supervision, clinical supervision, head nurses, career adaptability

\section{Introduction}

Supervision is the activity of management that has been familiarized as clinical supervision, and is a proper method for supporting, training, and discipline of manpower. In addition, it is an essential part of clinical practice, and it is considered the gatekeeper to profession. Moreover, supervision is helpful in identification of clinical problems and trained clinical supervisors can inform nurses what and when to do, while supervising. Thus, it aims for supporting, strengthening, motivating and encouraging personal and professional growth through the sharing of knowledge and experience to enhance their career adaptability and to be creative and innovative. Accordingly, it brings development to the organization (Cassedy, 2010; Koivu, et al., 2012).

In nursing, clinical supervision is a process between two or more professionals (novice nurse and practitioner nurse), involving the supervisors who use their knowledge and experience to assist their supervisees (nurses) to develop their practice, knowledge and values. During supervision, the two individuals should meet on a regular basis for education, monitoring, assessing, examining practice and receiving feedback at work, which leads to the development of professional skills (Manchester Mental Health and Social Care Trust, 2014).

Therefore, supervisors should meet specific attributes as; communication skills, leadership behavior, emotional control, decision making skills, personal qualification, professionals and technical knowledge, flexibility, integrity, openness, collaboration, appreciation of diversity, high levels of self-awareness, and demonstrating the capacity to create culturally safe environments, and having adequate preparation for their role via continuous training and education (Berggren and Severinsson,2011). Nature of supervision differs according to kind of work to be supervised, the type of people to be supervised, the extent of supervisor's responsibility and the level of supervision (Eldeeb, 2010).

Clinical supervision included three main functions namely; educational/formative which focuses on developing supervisee's skills, understanding and abilities. While, managerial/ administrative/normative function focuses on developing supervisee understands of the professional and ethical requirements of their practice. And supportive / restorative function focuses on developing supervisee's ability to adapt with their work for achieving personnel and organizational goals (Marquis and Huston, 2015). 
There are diverse ways in format and techniques that clinical supervision is handled inside the work as; individual supervision; is that the cornerstone of skilled development and it may be one-to-one, or face-to-face between a nurse and a clinical supervisor. Many alternative methods are used throughout individual supervision, comparable to self-report, process notes, audiotape, or videotape. The further form live supervision; is the mixture of direct observation of the counseling session and a few technique that permits the supervisor to talk with and influence the work of the supervisee. While, group supervision; is a group of nurses who meet with clinical supervisor and share vital components of their case, this manner lets a nurse to receive multiple viewpoints of their case, that successively provides them with the flexibility to remain broad-minded throughout the supervision process (Francke and Graaff, 2012; Salimi and Dehghani,2013; Bernard and Goodyear, 2014).

Moreover, it is a dynamic process that can be positive or negative, healthy or dysfunctional, within work environment. Sometimes it can be negative when supervisors act as inspectors rather than facilitators, do not develop nurses, make inadequate suggestions, provide inadequate guidance and education, do not provide feedback or give more negative comments than positive, and do not motivate nurses. On the other hand, it is positive when supervisors support staff to adapt with different situation in clinical practice (Koivu et al., 2011).

Adaptation may be challenging, especially for those who have been in the career for long periods of time, such as middleaged and older workers. It is measured as an overall perceived competence and motivation to cope with changing circumstances. Additionally, career adaptability is the readiness to cope with the predictable tasks of preparing for and participating in the work role and with the unpredictable adjustments prompted by the changes in work and work conditions (Van Vianen et al., 2010; Barto et al., 2015).

Career adaptability is a central construct in career preparation and refers to the attitudes, beliefs and competencies comprises as four dimensions (4Cs namely; concern, control, confidence and curiosity. Each of those represents an adaptive resource or strategy that individuals could use to adapt with tasks, while constructing their careers (Rudolph et al., 2015). Career adaptabilities dimensions are significantly related to the variety of outcomes such as job and work satisfaction that come from effective supervision (Taber and Blankemeyer, 2015).

The first dimension is career concern revenue "looking ahead to one's future" so; it involves setting career goals and is thus closely linked to career planning. While, career control is the second dimension that means" knowing what career to pursue" thus, represents self-discipline and willingness and to take responsibility with one's career. In addition, the third dimension is career curiosity distinct "looking around at options" hence, shows the individuals' openness to the new experiences and dispositions to the self and environmental explorations related with career opportunities. Whereas, the fourth and final dimension career confidence refers to the belief of individuals to cope with the challenges in career development process accordingly, expecting to be able to solve complex problems while constructing one's career (Savickas\&Porfeli, 2012; Guan et al., 2013; Maggiori et al., 2013). The total level of one's career adaptability is reflected in the presence of each of the four dimensions, but more importantly in the ability to adequately use them (Koen et al., 2012; Tolentino et al., 2014; Zacher, 2015).

\subsection{Significance of the Study}

Supervision is one of the most significant career management techniques which support nurses' career developments in conjunction with other mechanisms. Also, it is help nurses to adapt to different work situations. Because, rapidly changing global conditions and life-span career approaches need nurses to have career adaptabilities which facilitate them to meet requirement of career development process and employment demands (Tuna et al., 2014).

From the work experience of the researcher at Benha University Hospital, it was observed that nurse managers, lack the essential administrative skills and prerequisite for effective clinical supervision. So, it hopes that this clinical supervision training program will enhance their skills and provide them with basic and essential principles of effective clinical supervision to the development and skilled workforce which in turn can contribute positively to staff career adaptability.

\subsection{Aim of the Study}

This study was aimed to evaluate the effect of education program about clinical supervision for first line managers (head nurses and their assistants') on staff nurses' career adaptability.

\subsection{Research Hypotheses}

- There will be difference in first line managers' knowledge test score of clinical supervision after the program implementation compared to before.

- There will be difference in scores of first line managers' performances regarding clinical supervision after the program implementation compared to before.

- There will be difference in scores of career adaptability as reported by staff nurses after the program implementation compared to before.

\section{Subjects and Methods}

\subsection{Research Design}

Quasi experimental design was utilized in this study. 


\subsection{Setting}

units.

The study was conducted in all units at Benha University Hospital, the total number of the studied units were (57)

\subsection{Subjects}

\subsubsection{Subject Size}

Subjects of the study included two groups namely; first line managers group: All the available head nurses and their assistants (88) working in the above-mentioned study setting with at least one year of job experience and agree to participate after clarification purpose of the study. Staff nurses' group: included convenient sample of staff nurses (176) who are working in the above-mentioned study setting and with at least one year of job experience, available at the time of study, and agree to participate after clarification of purpose of the study.

\subsection{Tools of Data Collection}

Data for the present study was collected using the following three tools:

\subsubsection{Clinical Supervision Knowledge Questionnaire}

A structured questionnaire developed by the researchers based on the review of the related literature (Cassedy, 2010; Eldeeb, 2010;Bernard and Goodyear, 2014; and Manchester Mental Health and Social Care Trust, 2014) to assess head nurses and their assistants' knowledge regarding clinical supervision. It consisted of two parts: Part one; include personal characteristics of head nurses and their assistants' as; age, sex, marital status, educational qualification, previous training regarding supervision and experience years. Part two: clinical supervision knowledge questionnaire. It consists of 25 questions (true and false "15" questions and multiple choice "10" questions).

\subsubsection{Scoring System}

The questions were scored as "1" for correct answer, and "zero" for incorrect answer. The total scores were summed up and clinical supervision knowledge expressed as follow; $<60 \%$ of total score meansunsatisfactory knowledge and $\geq 60$ $\%$ of total score mean satisfactory knowledge.

\subsubsection{Observational Checklist of First Line Managers' Performance}

It was developed by El Shahat (2014) to assess head nurses and their assistants" performance related to clinical supervision models. It included three models, model (1): Normative (Managerial); this model is subdivided under (13) items, model (2): Formative (Educational); this model is subdivided under (11) items mode (3): Restorative (Supportive); this model is subdivided under (12) items.

\subsubsection{Scoring System}

Each question was granted one point for the done and zero for not done. The total score for all questions was 36. Total scores were expressed as percentages. Level of performance was considered high if the percent $\geq 75 \%$ (score $\geq 27$ ), moderate: $60 \%$ - < $75 \%$ (score $(22$ - <27) and low: <60\% (score <21).

\subsubsection{Career Adapt-Abilities Scale (CAAS)}

It was adopted by Porfeli and Savickas (2012) to assess staff nurses' level of career adaptabilities. It consisted of 24 items divided into four main dimensions; Concern (6 items), Control (6 items), Curiosity (6 items) and Confidence (6 items).

\subsubsection{Scoring System}

Using a five-point Likert scale as follow: not strong (1 point), somewhat strong ( 2 point), strong ( 3 point), very strong ( 3 point) and strongest ( 5 point) and total score (120). The score of each dimension summed up and converted to percent score. Level of career adaptabilities is considered high if the percent ( $\geq 75 \%)$ (Score $\geq 90$ ), moderate $(60 \%$ - $<$ $75 \%$ ) (Score from $72-<90)$ and low $<(60 \%)$ (Score $<72)$.

\subsection{Methods}

\subsubsection{Operational Design}

The operational design of the current study included the preparatory phase, content validity and reliability, pilot study and field work.

\subsubsection{Tools Validity}

Study tools contents were developed and tested for its validity by jury of 5 academic staff in nursing administration at different faculties of nursing. The validity of the tools aimed to judge its clarity, comprehensiveness, relevance and accuracy. All of their comments were taken into consideration; some items were re-phrased 


\subsubsection{Tools Reliability}

The Cronbach's Alpha test was done for study tools. The calculated reliability was ( $r=92 \%, 89.3 \%$ \& 88.6\%) for clinical supervision knowledge questionnaire, observational checklist of first line managers' performance and career adaptabilities scale respectively and that within the accepted limit.

\subsubsection{Approval}

An official permission was obtained from the hospital authorities in the identified setting to collect the necessary data and implement the program after explaining its purpose.

\subsubsection{Pilot Study}

A pilot study was carried out on (8 first line managers and 18 staff nurses) who were constituted $10 \%$ of the current study sample before starting the actual data collection to ascertain the clarity and applicability of the study tools. It also, needed to estimate the time necessary to fill in these tools. Based on the pilot study analysis, no modifications were done in the clinical supervision knowledge questionnaire as well as the career adapt-abilities scale.

\subsubsection{Ethical Considerations}

Purpose and expected outcomes of the study were explained to each study subject. They were secured that all the gathered data will be used for the research purpose only, the study is harmless and their approval to participate is a prerequisite to be included in the study. Each subject was assured that they can withdraw whenever they want.

\subsubsection{Field Work} following:

The study was carried out for (Ten months) from at the beginning of January to the end of October 2016 as the

- Pre-implementation phase (Initial assessment): Preparation of data collection tools and the training program about clinical supervision based on a review of recent national and international related literature using journals, periodicals, textbooks, internet and theoretical knowledge of the various aspects concerning the topic (from the beginning of January to the end of February 2016). Contents of the program included: concept and importance of clinical supervision, component and stages of practicing clinical supervision, methods and models of clinical supervision and essential skills of clinical supervisor.

- Implementation phase (intervention): was carried out from the beginning of March 2016 to end of May 2016. At the beginning; studied first line managers divided into 8 groups (10 nurses in each group) then the preprogram tests were fulfilled by the head nurses and their assistants' before beginning of the training program. Clinical supervision Knowledge questionnaire took from 25-30 minutes to be completed, while the researcher took about 45 - 60 minutes to observe the first line nurse manager's performance and staff nurses took about 20-25 minute for completing career adapt-abilities scale. This pre-study test was designed to allow the researchers collect a baseline assessment of first line manager' knowledge and skills and staff nurses' knowledge in order to compare it with immediate post and follow-up program. The data collected four days/ week in the morning and afternoon at the beginning of March 2016 to the end of March 2016.

- After the questionnaires were completed, the training program was implemented by the researchers. The time plan of the program implemented over the period from the beginning of April 2016 to end of May 2016. The training program has taken 12hours for each group distributed as the following; 8 sessions, 1.30hour/ session, 2 days/ week in the morning and afternoon shift, at the beginning of the program sessions, an orientation to the program and its purpose took place and the nurse managers were informed about the time and place of sessions which were carried out at the training department lecture room. Each session was started by setting objectives and overview of the new topic, at the end of each session the nurse managers' questions were discussed. Each group perceived the program content using the same teaching strategies and handout, methods of teaching were used as the following; lecture, group discussion, role play and brain storming. Teaching and instructional media included the following; hand out, CD and power point presentation. Each researcher implements the program with two groups in the day by using the same available resources, relevant contents and instructional strategies for each session.

- Evaluation phase: during this phase, the effect of educational program was evaluated; it was carried out immediately after the program implementation and follow up after 3 months of intervention by using the same format of tools which used before the program implementation. The time of the data collection lasted for five months from the beginning of June 2016 to end of October 2016.

\subsubsection{Statistical Design}

The collected data organized, tabulated and statistical analyzed using statistical package for social science (SPSS) version 21 for windows, running on IBM compatible computer. Descriptive statistics were applied (e.g. frequency, percentages, mean and standard deviation). Test of significance, Chi-square "X2" and correlation coefficient ( $r$ ) were used. A significant level value was considered when $\mathrm{p}<0.05$ and a highly significant level value was considered when $\mathrm{p}<0.001$. No statistical significance difference was considered when $p>0.5$. 


\section{Results}

- Table (1): depicted distribution of first line managers and staff nurses according to their demographic characteristics, where more than two fifths $(43.2 \%)$ had age from $25<35$ years with a mean age of $34.07 \pm 8.83$ while $49.4 \%$ of staff nurses had age $\geq 45$ with a mean age of $36.84 \pm 9.41$. in addition, the majority of both first line managers and staff nurses $(95.5 \%, 80.7 \%, 75.1 \%, 51.7 \%$ respectively) were female and married. As regard to Educational Qualification, more than half of first line managers (58.0 \%) had Bachelor of nursing while less than half of staff nurses (47.2\%) had Technical nursing institute. In relation to years of experience, the highest percent of both first line managers and staff nurses $(52.3 \%, 37.5 \%$ respectively) had $15<25$ years. Also, the majority of first line managers (81.8 \%) hadn't previous clinical supervision training.

- Figure (1): showed level of first line managers` knowledge regarding clinical supervision thorough program. It was observed that there was a highly statistical significant improvement in first line managers `knowledge scores regarding clinical supervision immediate post program (88.6\%) and three months follow up the program (76.1\%) compared to preprogram scores $(9.1 \%)$.

- Table (2): indicated that there was a highly significant improvement in clinical supervision performance assigned by first line managers throughout the three phases of the program; pre, immediate post program, and follow up after three months. during pre-program the highest percentages of them $(27.3 \%)$ implemented Normative (Managerial model) while immediate post program, most of them $(93.2 \%, 96.6 \%)$ implemented normative (managerial) and restorative (supportive) models of clinical supervision respectively and still following these models at follow up period.

- Figure (2): displayed level of clinical supervision performance among first line managers thorough program. It was observed that there was a highly statistical significant improvement in first line managers 'clinical supervision performance immediate post program (77.3\%) and slightly decreased three months follow up the program $(62.5 \%)$ compared to preprogram scores.

- Table (3): represented mean and standard deviation of career adaptability among staff nurses' thorough program. It indicated that there was a highly statistical significant improvement in staff nurses' level of career adaptability. The total mean scores of staff nurses' career adaptability preprogram were $(28.85 \pm 7.01)$ and immediately post and 3 months post program were $(99.25 \pm 2.60,90.56 \pm 3.81)$ respectively.

- Figure (3): portrayed that there was a highly statistical significant improvement in staff nurses' clinical level of career adaptability immediate post program (94.3\%) and slightly decreased three months follow up the program $(69.9 \%)$ compared to preprogram scores.

- Table (4): demonstrated that there was a highly statistical positive correlation between first line managers' clinical supervision performance and their years of experience and education qualification. Also, there was a highly statistical positive correlation between staff nurses' Career adaptability and their years of experience and education qualification.

- Table (5): Shows that there was a highly statistical positive correlation between first line managers' clinical supervision performance and staff nurses' career adaptability. 


\begin{tabular}{|c|c|c|c|c|c|}
\hline \multicolumn{2}{|c|}{ Variables } & \multicolumn{2}{|c|}{ First line Managers (88) } & \multicolumn{2}{|c|}{ Staff Nurses (176) } \\
\hline & & No & $\%$ & No & $\%$ \\
\hline \multirow[t]{5}{*}{ Age in years } & $<25$ & 17 & 19.3 & 22 & 12.5 \\
\hline & $25<35$ & 38 & 43.2 & 32 & 18.2 \\
\hline & $35<45$ & 24 & 27.3 & 87 & 49.4 \\
\hline & $\geq 45$ & 9 & 10.2 & 35 & 19.9 \\
\hline & Mean \pm SD & \multicolumn{2}{|c|}{$34.07 \pm 8.83$} & \multicolumn{2}{|c|}{$36.84 \pm 9.41$} \\
\hline \multirow[t]{2}{*}{ Sex } & Male & 4 & 4.5 & 42 & 23.9 \\
\hline & Female & 84 & 95.5 & 134 & 76.1 \\
\hline \multirow[t]{4}{*}{ level of Education } & Secondary nursing education & 15 & 17.0 & 54 & 30.7 \\
\hline & Technical nursing institute & 19 & 21.6 & 83 & 47.2 \\
\hline & Bachelor of nursing & 51 & 58.0 & 39 & 22.1 \\
\hline & Post graduate nursing education & 3 & 3.4 & 0 & 0.0 \\
\hline \multirow[t]{5}{*}{ Years of experience } & $<5$ & 5 & 5.7 & 23 & 13.1 \\
\hline & $5<15$ & 28 & 31.8 & 46 & 26.1 \\
\hline & $15<25$ & 46 & 52.3 & 66 & 37.5 \\
\hline & $\geq 25$ & 9 & 10.2 & 41 & 23.3 \\
\hline & Mean \pm SD & \multicolumn{2}{|c|}{$17.53 \pm 7.78$} & \multicolumn{2}{|c|}{$16.77 \pm 8.84$} \\
\hline \multirow[t]{3}{*}{ Marital status } & Single & 5 & 5.7 & 39 & 22.1 \\
\hline & Married & 71 & 80.7 & 91 & 51.7 \\
\hline & Others & 12 & 13.6 & 46 & 26.2 \\
\hline \multirow{2}{*}{$\begin{array}{c}\text { Previous clinical } \\
\text { supervision training }\end{array}$} & Yes & 16 & 18.2 & & \\
\hline & No & 72 & 81.8 & & \\
\hline
\end{tabular}

Table 1: Personal Characteristics of the Studied Participants

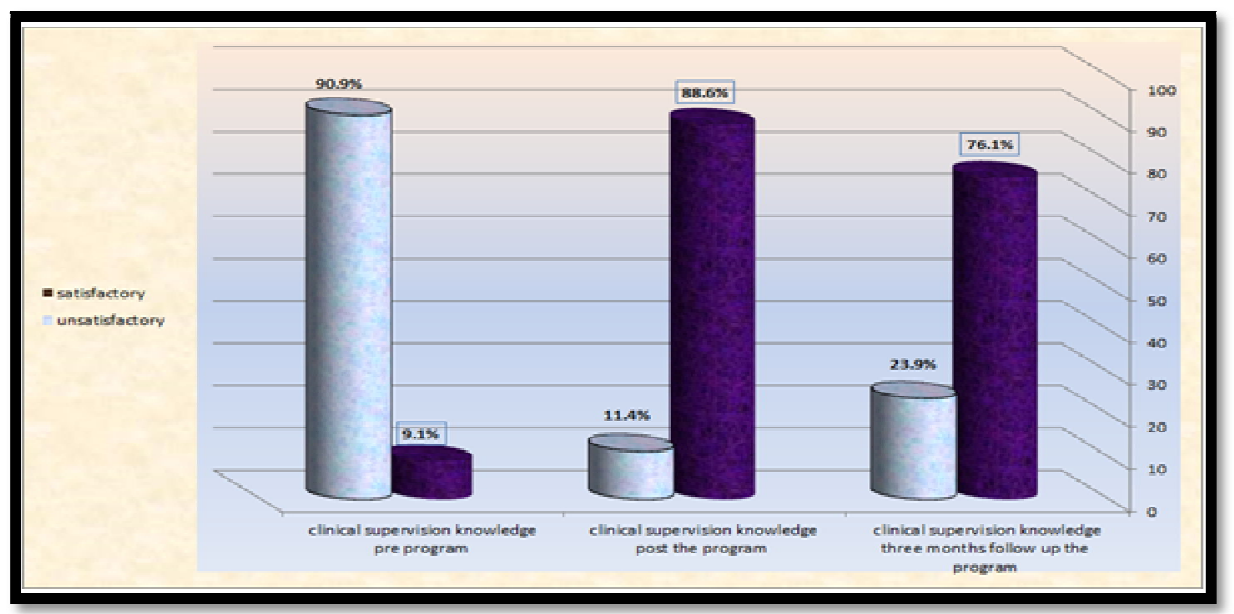

Figure 1: Level of First Line Managers` Knowledge Regarding Clinical Supervision thorough Program (N=88)

\begin{tabular}{|c|c|c|c|c|c|c|c|c|c|c|}
\hline \multirow{3}{*}{$\begin{array}{c}\text { Clinical } \\
\text { supervision } \\
\text { models }\end{array}$} & \multicolumn{6}{|c|}{ First line managers` $(n=88)$. } & \multirow{3}{*}{$\begin{array}{c}\mathrm{X}^{2} \\
\text { Test } \\
\text { (1) }\end{array}$} & \multirow{3}{*}{ P-Value } & \multirow{3}{*}{$\begin{array}{c}\mathbf{X}^{2} \\
\text { Test (2) }\end{array}$} & \multirow{3}{*}{ P-Value } \\
\hline & \multicolumn{2}{|c|}{ Pre-program } & \multicolumn{2}{|c|}{$\begin{array}{c}\text { Post- } \\
\text { program }\end{array}$} & \multicolumn{2}{|c|}{$\begin{array}{l}\text { Follow up- } \\
\text { program }\end{array}$} & & & & \\
\hline & No & $\%$ & No & $\%$ & No & $\%$ & & & & \\
\hline \multicolumn{7}{|c|}{ Normative (Managerial) } & \multirow{9}{*}{163.66} & \multirow{9}{*}{$\varangle 0.001^{* *}$} & \multirow{9}{*}{137.61} & \multirow{9}{*}{$\varangle 0.001 * *$} \\
\hline Done & 24 & 27.3 & 82 & 93.2 & 76 & 86.4 & & & & \\
\hline Not Done & 64 & 72.7 & 6 & 6.8 & 12 & 13.6 & & & & \\
\hline \multicolumn{7}{|c|}{ Formative (Educational) } & & & & \\
\hline Done & 16 & 18.1 & 79 & 89.8 & 70 & 79.5 & & & & \\
\hline Not Done & 72 & 81.9 & 9 & 10.0 & 18 & 20.5 & & & & \\
\hline \multicolumn{7}{|c|}{ Restorative (Supportive) } & & & & \\
\hline Done & 18 & 20.4 & 85 & 96.6 & 77 & 87.5 & & & & \\
\hline Not Done & 70 & 79.6 & 3 & 3.4 & 11 & 12.5 & & & & \\
\hline
\end{tabular}

Table 2: Comparisons of Clinical Supervision Performance among First Line Managers thorough Program $(\mathrm{N}=88)$

**A High Statistical Significant Difference $(\mathrm{P} \leq 0.001)$

$X 2 \& P$ Value Test (1): between Pre-Program and Immediate Post Program $X 2 \&$ P Value Test (2): between Pre-Program and Follow up Program 




Figure 2: Total Level of Clinical Supervision Performance among First Line Managers thorough Program $(\mathrm{N}=88)$

\begin{tabular}{|c|c|c|c|c|c|c|c|c|}
\hline Dimension & $\begin{array}{l}\text { Max } \\
\text { score }\end{array}$ & $\begin{array}{c}\text { Pre-program } \\
\text { Mean } \pm \text { SD }\end{array}$ & $\begin{array}{c}\text { Post } \\
\text { program } \\
\text { Mean } \pm \text { SD }\end{array}$ & $\begin{array}{c}\text { Follow up } \\
\text { program } \\
\text { Mean } \pm \text { SD }\end{array}$ & $\begin{array}{c}\text { t-test } \\
1\end{array}$ & $\begin{array}{c}P \\
\text { value }\end{array}$ & $\begin{array}{l}\text { t-test } \\
2\end{array}$ & $\begin{array}{c}P \\
\text { value }\end{array}$ \\
\hline Concern & 30 & $7.02 \pm 2.03$ & $23.25 \pm 1.36$ & $21.24 \pm 1.29$ & \multirow{5}{*}{121.85} & \multirow{5}{*}{$\begin{array}{l}<0.001 * \\
\quad *\end{array}$} & \multirow{5}{*}{93.85} & \multirow{5}{*}{$\begin{array}{c}<0.001 * \\
*\end{array}$} \\
\hline Control & 30 & $7.86 \pm 2.12$ & $28.26 \pm 1.33$ & $25.68 \pm 0.97$ & & & & \\
\hline Curiosity & 30 & $6.55 \pm 1.34$ & $21.52 \pm 1.16$ & $19.00 \pm 1.46$ & & & & \\
\hline Confidence & 30 & $7.41 \pm 1.95$ & $26.20 \pm 0.60$ & $24.62 \pm 1.49$ & & & & \\
\hline Total & 120 & $28.85 \pm 7.01$ & $99.25 \pm 2.60$ & $90.56 \pm 3.81$ & & & & \\
\hline
\end{tabular}

Table 3: Mean and Standard Deviation of Career Adaptability Among

Staff Nurses' thorough Program ( $\mathrm{N}=176)$

**A High Statistical Significant Difference $(\mathrm{P} \leq 0.001)$

Paired T-Test 1: Pre \& Post

Paired T-Test 2: Pre \& Follow up

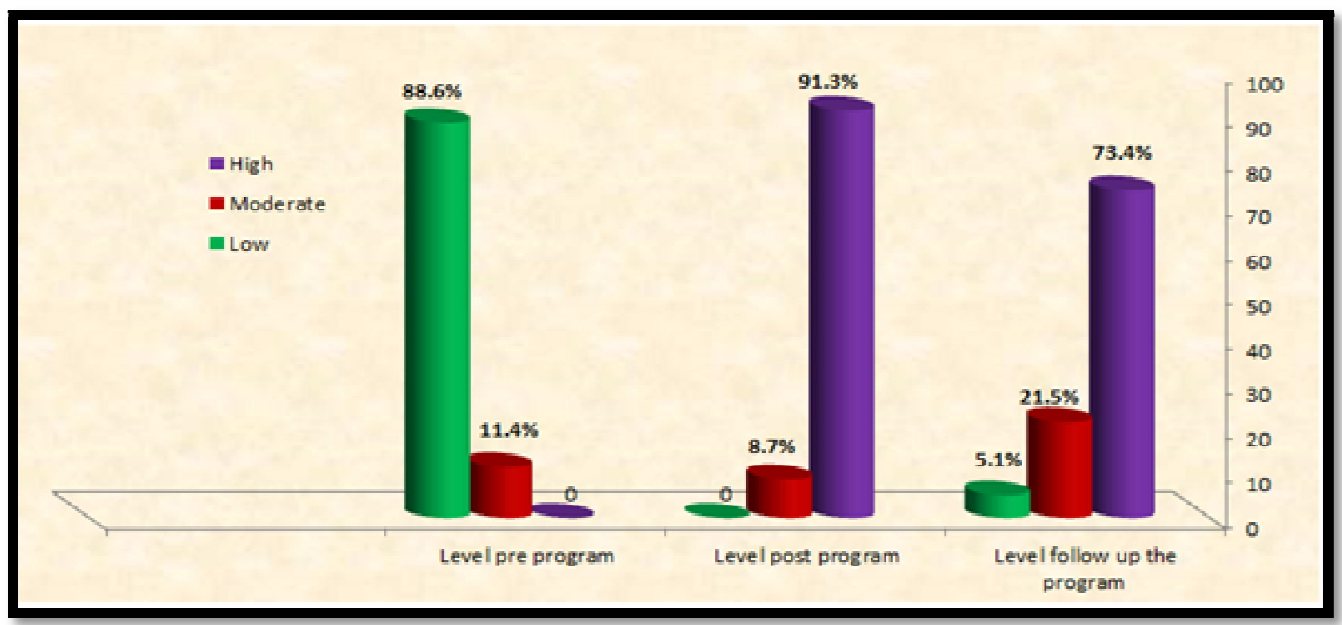

Figure 3: Total Level of Career Adaptability as Reported by Studied Staff Nurses' thorough Program (N=176)

\begin{tabular}{|c|c|c|c|c|c|c|c|c|}
\hline \multirow[t]{4}{*}{ Variables } & \multicolumn{8}{|c|}{ Personal Characteristics of Studied Participants } \\
\hline & \multicolumn{4}{|c|}{ First line managers (88) } & \multicolumn{4}{|c|}{ Staff nurses (176) } \\
\hline & \multicolumn{2}{|c|}{ Years of Experience } & \multicolumn{2}{|c|}{ Level of Education } & \multicolumn{2}{|c|}{ Years of Experience } & \multicolumn{2}{|c|}{ Level of Education } \\
\hline & $\mathrm{r}$ & P-value & $\mathrm{r}$ & P-value & $\mathrm{r}$ & P-value & $\mathrm{r}$ & P-value \\
\hline $\begin{array}{l}\text { Clinical supervision } \\
\text { performance }\end{array}$ & $0.681 * *$ & $\varangle 0.001 * *$ & $0.860^{* *}$ & $<0.001^{* *}$ & & & & \\
\hline Career adaptability & & & & & $0.521 * *$ & $<0.001 * *$ & $0.730 * *$ & $<0.001^{* *}$ \\
\hline
\end{tabular}

Table 4: Correlation between Clinical Supervision Performances, Level of Career Adaptability, Years of Experience, and Education Qualification of Studied Participants during Immediate Post Program Phase **A High Statistical Significant Difference (P $\leq$ 0.001) 


\begin{tabular}{|c|c|c|}
\hline \multirow{2}{*}{ Variable } & \multicolumn{2}{|c|}{ Overall Score for Career Adaptability } \\
\cline { 2 - 3 } & $\mathrm{r}$ & $\mathrm{p}$-value \\
\hline $\begin{array}{c}\text { Overall score of clinical supervision } \\
\text { performance }\end{array}$ & 0.830 & $<0.001^{* *}$ \\
\hline
\end{tabular}

Table 5: Correlation between Overall Score of Clinical Supervision

Performance and Career Adaptability

\section{Discussion}

Clinical supervision is a process of professional support and learning in which nurses are assisted in developing their practice through regular discussion time with experienced and knowledgeable colleagues. During clinical supervision nurses employ the processes of reflection in order to identify and meet their need for professional development. The purpose of clinical supervision is to improve nursing practice. In addition, clinical supervision provides an avenue for nurses to demonstrate active support for each other as professional colleagues. Through sharing and understanding they come to realize that they are 'not alone' in their feelings and perceptions, thus enhancing career adaptability (Cruz et al., 2012).

Concerning level of first line managers ' knowledge regarding clinical supervision thorough program, the results showed that there was a highly statistical significant improvement in first line managers' knowledge immediately and after 3 months of program. It could be inferred that the teaching program helped first line managers to improve their knowledge in clinical supervision and this improvement referred to the ability of first line managers to acquire knowledge, and the refreshing of information using different methods of active learning during implementation of program.

The previous result was in agreement with the result of El-Shahat (2014) who conducted a study entitled " The Effectiveness of Implementing Clinical Supervision Models on Head Nurses' Performance and Nurses' Job Satisfaction" and showed that there was a highly significant improvement of head nurses and their assistants' knowledge and responsibility perception related to clinical supervision pre, immediate, and three months post program implementation. Also, Al Zeney et al., (2017) who conducted a study entitled " Effect of Clinical Supervision Training Program for Nurse Managers on Quality of Nursing Care in Intensive Care Units" found a statistical significant differences and marked improvement in nurse managers total knowledge regarding clinical supervision as the highest percentage of them had high score immediately post program, and three months post program compared to preprogram.

In the same respect, Soliman (2014) found a significant improvement in head nurses' knowledge after attending educational program and emphasized the importance of educational opportunities to strengthen and update their knowledge and also empower them in their work. Moreover, Hasanin (2015) indicated that there were marked improvement of the level of knowledge attainment from the pretest, immediate, and two months post - tests.

According to first line managers' performance regarding clinical supervision, the results of the present study showed that there was a highly significant improvement in first line managers' performance regarding clinical supervision models (Normative (managerial), Formative (educational) and Restorative (supportive) throughout the different phases of the program; pre, immediate post program, and three months follow up. From the researchers opinions, the clinical supervision program for first line managers' was successful as it improved the first line managers' skills of supervision to practice their role and promote units supervision where they learned how to be effective leader, gained experiences in helping nurses how to apply technical skills in different clinical situations and in using different educational strategies in guiding their staff and acquired skills related to encouraging effective communication and team work among nurses and supporting nurse - patient caring relationship. In similar study of Al Zeney et al., (2017) it was noticed that there was a marked improvement in nurse manager's clinical supervision competencies immediately post program and three months post program compared to before implementation.

This result was supported by Sirola- Karvinen and Pirjo, et al., (2008) who conducted a study entitled "Administrative clinical supervision as evaluated by the first-line managers in one health care organization district" and found that the supervision program was very successful and there was significant improvement in level of nurse unit mangers responsibility as supervisors. Additionally, this result was consistent with Fulton et al., (2014) who found that there was a highly statistical significant improvement in nurses' performance related to clinical supervision immediately after program implementation, as significant differences was found between the mean pre and post - test knowledge score.

Moreover, this result was in agreement with El-Shahat (2014) who reported that there was a high statistical significant improvement in the performance head nurses and their assistants' clinical supervision performance in pre, immediate post program and follow up the program. In the same respect, Sharif and Masoumi (2014) reported that some of the head nurses (nursing unit manager) and staff nurses were very good in supervising in the clinical area. The head nurse can play an important role in nurses' self-confidence, promote role socialization, and encourage independence which leads to clinical competency.

Regarding staff nurses' career adaptability thorough program, the results of the present study revealed that there was a highly statistical significant improvement in staff nurses 'level of career adaptability regarding dimensions (concern, control, confidence and curiosity) immediate post program three months follow up the program compared to preprogram scores. This result could be explained in the light of the positive impact of the clinical supervision training program on quality of nursing care among staff nurses, as well as the improvement in the effectiveness of clinical supervision practices of their nurse managers which increase staff nurses' ability to adapt with and manage career changes and challenges in different situations for personnel and organizational development.

This was supported by Bocciardi (2017) who confirmed that training and career-development professionals can improve their understanding of which career-related skills and attitudes can increase one's capability to cope with sudden 
changes and instability of the current labour market. As well as, the current study finding was on the same line with Koen et al.( 2012) who conducted a study entitled " Training career adaptability to facilitate a successful school-to-work transition " and reported that the effects of the career adaptability training were investigated immediately after the training and six months later as the results showed that the development of career adaptability was significantly different for the training group as compared to the control group: the training group had increased in concern, control and curiosity, whereas the control group had not increased in concern and had even decreased in control and curiosity.

The results of the present study demonstrated that there was a highly statistical positive correlation between first line managers' clinical supervision performance and their years of experience and education qualification. This might be due to high-qualified head nurses with increased years of experience practice clinical supervision effectively as they exposed to different work conditions and acquired more experiences regarding how to supervise nursing work and this was confirmed through their academic education.

This result was incongruent El-Deghaidy and Nouby (2008) who said that there was no significant statistical relation between demographic data, head nurses' knowledge and practices scores as regards to clinical supervision. While El-Shahat (2014) found that there was highly statistical significant relation between head nurses and their assistants' level of knowledge and department, age, qualification and years of experience.

Furthermore, the results of the present study indicated that there was a highly statistical positive correlation between staff nurses' career adaptability and their years of experience and education qualification. From the research opinions, when nurses have high education with increased years of experience, this enable them how to adapt with their work as they possessed the required resources that function as self-regulation strategies which give them an opportunity to broaden, refine and eventually implement their self-concepts in occupational roles, thereby creating their work lives and building their careers. This was confirmed by McMahon et al., (2012) who conducted a study regarding " Career adaptability: A qualitative understanding from the stories of older women" and explored how this group of women who had more years of experience coped with and adapted to changes and transitions related to career.

As regard to correlation between clinical supervision performance and career adaptability. The results showed that there was a highly statistical positive correlation between first line managers' clinical supervision performance and staff nurses' career adaptability. This could be inferred that the clinical supervision program was successful in improving first line managers' knowledge and performance related to clinical supervision models related to supervision through learning, supporting and facilitating nurses' career adaptability under changing circumstances. This result was supported by Abo Hashish (2010) who conducted a study entitled "Effect of clinical supervision training program for first-line nurse managers on quality of care and job satisfaction" and found that, there was a positive effect of clinical supervision training program for first-line nurse managers on quality of care and job satisfaction.

\section{Recommendations}

The findings of the study suggest that:

- Hospital administration should conduct workshops for increasing awareness of head nurses about clinical supervision models and how to apply them in their work.

- $\quad$ Providing continuous in-service training and education programs for increasing skills of head nurses, supervisors and staff nurses regarding supervision.

- $\quad$ Setting clear responsibilities for both nursing supervisor and supervisee through a constructive clinical supervision policies and procedures.

- Providing healthy work environment that support nurses to reflect on their personal and professional workrelated issues with their clinical supervisors that help in enhancing their career adaptability.

- Integrating career adaptability in nursing education.

- Further research should be made to measure and investigate adaptive behaviors such as career planning, selfefficacy and career exploration.

\section{Conclusions}

There was a highly statistical significant improvement in first line managers' knowledge and performance regarding clinical supervision immediate post program and three months follow up the program compared to preprogram scores. There was a highly statistical significant improvement in staff nurses' level of career adaptability immediate post program and three months follow up the program compared to preprogram scores. In addition, there was a highly statistical positive correlation between first line managers' clinical supervision performance and staff nurses' career adaptability.

\section{Acknowledgements}

The researchers would like to express gratitude and appreciations to (88) first line managers and 176 staff nurses who participated in this study for their effective cooperation.

\section{References}

i. Abou Hashish, E. (2010): Effect of clinical supervision training program for first-line nurse managers on quality of care and job satisfaction, Doctorate Thesis Faculty of nursing, University of Alexandria.

ii. Al Zeney, S., Seada, A. and Etewy, E. (2017): Effect of Clinical Supervision Training Program for Nurse Managers on Quality of Nursing Care in Intensive Care Units, international Journal of Nursing Didactics, 7(08),pp.8-17. 
Barto, H., Lambert, S., and Brott, P. (2015): Career adaptability, resiliency and perceived obstacles to career development of adolescent mothers. The Professional Counselor, 5(1), 53-66.

iii. Berggren, I. and Severinsson, E. (2011): The State of the Science of Clinical Supervision in Europe. In: Cutcliffe, J., Hyrkäs, K. and Fowler, J., Eds., Fundamental International Themes, Routledge, Milton Park, 327-337.

iv. Bernard, M., and Goodyear, K., (2014): Fundamentals of clinical supervision, 4th edition, Boston, MA: Pearson Education.

v. Bocciardi, F.(2017): Career adaptability as a strategic competence for career development: An exploratory study of its key predictors, European Journal Of Training And Development, (41)1, available on https:/ / www .emeraldinsight.com/ doi/ full/ 10.1108/ EJTD-07-2016-0049.

vi. Cassedy, P. (2010): First steps in clinical supervision a guide for health care professionals, McGraw-Hill Education Co, www .openup.co.uk PDF. P.5.

vii. Cruz, S. carvalho, L. and souse, P. (2012): Clinical Supervision in Nursing: The (un)Known Phenomenon, ProcediaSocial and Behavioral Science, 69, 864-873.

viii. El- Deghaidy, H., and Nouby, A. (2008): Effectiveness of blended E. learning cooperative approach in an Egyptian teacher education program, Journal of Computer and Education.

ix. El Shahat, M. (2014): The Effectiveness of Implementing Clinical Supervision Models on Head Nurses' Performance and Nurses' Job Satisfaction at Benha University Hospital, Unpublished Doctorate Thesis, Faculty of Nursing, Benha University.

x. El deeb, G. (2010): Impact of a clinical supervision program on unit managers' skills at Menoufyia University Hospital, Unpublished Doctorate Thesis, Faculty of Nursing, Menofia University

xi. Francke, A. L. and Graaff, F.M. (2012): The effects of group supervision of nurses: A systematic literature review. International Journal of Nursing Studies: 49(9), 1165-1179.

xii. Fulton, J., Lyon, B., L., and Goudreau, K. (2014): Foundations of clinical nurse specialist practice, 2nd ed., Springer Publishing Company in United States of America.

xiii. Guan, Y.J., Deng, H., Sun, J. Q., Wang, Y. N., Cai, Z. J. Ye, L. H. and Li, Y. H. (2013): Career adaptability, job search selfefficacy and outcomes: A three-wave investigation among Chinese university graduates. Journal of Vocational Behavior, 83(3), 561-570.

xiv. Hasanin, A. (2015): Designing Electronic Clinical Administrative Records and Reports for Fourth Year Nursing Students, Unpublished Doctorate thesis, Faculty of Nursing, Benha University. pp. 56-59.

xv. Helen, T. and House, D. (2010): Clinical supervision toolkit for professionals working with children who have palliative care needs. P.20. Available at: https:/ / www.togetherforshortlives.org.uk/ wpcontent/ uploads/ 01/ ExRes-Helen-and-Douglas-House-Clinical-Supervision-Toolkit.pdf

xvi. Koen, J., Klehe, U. and Van Vianen, A. (2012): Training career adaptability to facilitate a successful school-to-work transition, Journal of Vocational Behavior 81, PP.395-408.

xvii. Koivu, A, Hyrkäs, K. and Saarinen, P. (2011): Who attends clinical supervision? The uptake of clinical supervision by hospital nurses. Journal of Nursing Management, 19, 69-79.

xviii. Koivu, A. Saarinen, P, and Hyrkas, K. (2012): Who benefits from clinical supervision and how? The association between clinical supervision and the work-related well-being of female hospital nurses. P. 86.

xix. Maggiori, C., Johnston, C., Krings, F., Massoudi, K., and Rossier, J. (2013):The role of career adaptability and work conditions on general and professional well-being. Journal of Vocational Behavior, 83, 437-449. doi:10.1016/j.jvb.2013.07.001.

xx. Manchester Mental Health and Social Care Trust (2014): Overarching supervision policy: Clinical/ professional and management supervision. P.8 Available at: www.mhsc. nhs.uk / overarching \% 20 super vision $\% 20$ p.

xxi. Marquis B, L, and Huston C, J. (2015) :Leadership Roles and Management Functions in Nursing: Theory and Application. 8th ed., Wolters Kluwer/ Lippincott Williams and Wilkins, Philadelphia.

xxii. McMahon, M., Watson, M. and Bimrose, G. (2012): Career adaptability: A qualitative understanding from the stories of older women, Journal of Vocational Behavior, (80)3, PP. 762-768.

xxiii. Porfeli, E. J., and Savickas, M. L. (2012): Career Adapt-Abilities Scale-USA Form: Psychometric properties and relation to vocational identity. Journal of Vocational Behavior, 80(3), 748- 753. doi: 10.1016/ j.jvb .2012 .01 .00.

xxiv. Rudolph, C.W., Lavignea, K.M. and Zacherb, H. (2015): Career adaptability: A meta-analysis of relationships with measures of adaptivity, adapting responses, and adaptation results. Journal of Vocational Behavior, 98, 17-34.

xxv. Salimi, T., and Dehghani, H.( 2013): Clinical supervision in nursing education: definitions and models. Iran J Med Educ., 13(3):179-87.

xxvi. Savickas, M. L., and Porfeli, E. J. (2012): Career adapt-abilities scale: Construction, reliability, and measurement equivalence across 13 countries. Journal of Vocational Behavior, 80(3), 661-673.

xxvii. Sharif, F. andMasoumi, S. (2014): A qualitative study of nursing student experiences of clinical practice. Bio Med Central Nursing. Retrieved in: 8/ 8/ 2014. Available at: http:/ / www. biomedcentral.com/ 1472-6955/ 4/ 6.

xxviii. Sirola- Karvinen, P. and Hyrkas, K. (2008): Administrative clinical supervision as evaluated by the first-line managers in one health care organization district. Journals Nursing Management; 16 (5): 588-600. Available at: http:/ / www.n cbi.nlm. nih.gov/ pub med/ .

xxix. Soliman, E. (2014): Effect of an Educational Program about Intradepartmental Communication among Nurses on Nurses' Empowerment, Unpublished Doctorate Thesis, Faculty of Nursing, Benha University.

xxx. Taber, B. J., and Blankemeyer, M. (2015): Future work self and career adaptability in the prediction of proactive career behaviors. Journal of Vocational Behavior, 86, 20-27. 
xxxi. Tolentino, L. R., James, M. G., Lu, V. N., Restubog, S. L. D., Bordia, P. and Plewa, C. (2014): Career adaptation: The relation of adaptability to goal orientation, proactive personality, and career optimism. Journal of Vocational Behavior, 84, 39-48.

xxxii. Tuna, M., Kanten, P., Yeşiltaş, M., Kanten, S. and Alparslan, A.M. (2014): The Effect of Academic Advising on Career Adaptabilities: A Study on Tourism and Hotel Management' Students, The Macrotheme Review, 3, 139-155.

xxxiii. Van Vianen, A. E. M., De Pater, I. E., and Preenen, P. T. Y. (2010): Career management: Taking control of the quality of career experiences. In J. A. Athanasou\& R. Van Esbroeck (Eds.), International Handbook of Career Guidance (pp. 283-301). London, UK: Springer.

xxxiv. Zacher, H. (2015): Daily manifestations of career adaptability: relationships with job and career outcomes. Journal of Vocational Behavior, 91, 76-86. 